\title{
IMPLEMENTASI MANAJEMEN KURIKULUM DALAM MENINGKATAN MUTU PENDIDIKAN DI SMP PGRI 1 PULAUPANGGUNG, KABUPATEN TANGGAMUS.
}

\author{
Mega Apriyani, Eri Purwanti, Adhar Al Mursyid \\ stitpringsewu@gmail.com, stitpringsewu@gmail.com,ptipd@radenintan.ac.id. \\ Jl. Raya Wonokriyo Gadingrejo Pringsewu
}

\begin{abstract}
This research is used to study Learning Curriculum Management in Improving Education Quality in SMP PGRI 1 Pulaupanggung, describing the implementation of management learning curriculum in order to improve the quality of education in SMP PGRI 1 Pulaupanggung, Tanggamus District.

The results show that a). The curriculum planning at SMP PGRI 1 Pulaupanggung is based on the previous evaluation results and the planning of future targets and programs compiled by the principal with all subordinate staff. b) .The organizing of the curriculum includes dividing the teaching tasks for teachers according to their respective areas of expertise, striving for teachers to teach 5 days a week, schedule remedial activities, conduct lessons and try out, schedule an extra curricular curriculum, teaching for teachers about science and technology, and arranging a schedule of teacher meetings in turns. c) .The curriculum implementation includes early learning activities, learning methods, learning media, end activities of learning. d). The curriculum evaluation is using the form of evaluation of cognitive aspects, affective aspects and psychomotor aspects.
\end{abstract}

\begin{abstract}
Abstrak
Penelitian ini digunanakan untuk mengkaji mengenai Manajemen Kurikulum Pembelajaran dalam Meningkatkan Mutu Pendidikan di SMP PGRI 1 Pulaupanggung, mendeskripsikan tentang implementasi manajamen kurikulum pembelajaran agar dapat meningkatkan mutu pendidikan di SMP PGRI 1 Pulaupanggung, Kabupaten Tanggamus.

Hasil penelitian menunjukkan bahwa a).Perencanaan kurikulum di SMP PGRI 1 Pulaupanggung ini berdasarkan pada hasil evaluasi sebelumnya dan perencanaan target dan program kedepan yang disusun oleh kepala sekolah dengan seluruh staf bawahannya. b).Pengorganisasian kurikulum meliputi membagi tugas mengajar bagi guru sesuai dengan bidang keahlian masing-masing, mengupayakan agar guru mengajar 5 hari dalam 1 minggu, menyususn jadwal kegiatan perbaikan/remidi, mengadakan les dan try out, menyususn jadwal kegiaatn ektra kurikuler, menyusun jadwal pengajaran bagi guru tentang IPTEK, dan menyusun jadwal pertemuan guru-guru secara bergiliran.c).Pelaksanaan kurikulum meliputi kegiatan awal pembelajaran,Metode pembelajaran, Media pembelajaran, kegiatan akhir pembelajaran. d). Evaluasi kurikulum yaitu menggunakan bentuk evaluasi aspek kognitif, aspek afektif dan aspek psikomotorik.
\end{abstract}

Kata Kunci : Kurikulum Pembelajaran, Mutu Pendidikan, Kabupaten Tanggamus. 


\section{A. PENDAHULUAN}

Istilah Implementasi mungkin tidak begitu awam digunakan dalam percakapan sehari-hari, hanya dalam konteks-konteks tertentu saja, secara singkat definisi implementasi dikemukakan menurut KKBI (Kamus Besar Bahasa Indonesia), yakni pelaksanaann atau penerapan.

Satu hal yang harus diperhatikan dalam Implementasi harus sesuai dengan rencana yang telah dibuat dan disempurnakan. Melenceng sedikit saja dari rencana awal akan membuat penerapan Implementasi menjadi percuma atau sia-sia.

Manajemen berasal dari bahasa inggris "management" dengan kata kerja to manage yang artinya mengatur.Pengaturan dilakukan melalui proses dan diatur berdasarkan urutan dari fungsi-fungsi manajemen.jadi, manajemen itu merupakan suatu proses untuk mewujudkan tujuan yang diinginkan.

Pada hakikatnya, setiap manusia merupakan manajer. Karena dalam kehidupannya, setiap manusia akan senantiasa menerapkan manajemen, walaupun bagi diri atau keluarganya sendiri. Penerapan manajemen dalam kehidupan manusia ini merupakan kebutuhan mendasar untuk meraih tujuan atau cita-cita yang diinginkan. Dalam konteks yang sedemikian ini, manusia dapat dikatakan telah menerapkan manajemen, walaupun masih secara alamiah. Penerapan manajemen secara alamiah semacam ini sangat berpotensi berujung pada kesalahan atau bahkan kegagalan.

Untuk dapat menerapkan konsep manajemen secara profesional, persyaratan utama yang harus dimiliki adalah pemahaman atas prinsip dan teori manajemen. Karena dengan memahami prinsip dan teori manajemen, manusia akan dapat menyusun kerangka dasar kerja, untuk melaksanakan tugas-tugas manajerial tersebut secara lebih professional.

Dalam sistem pendidikan nasional Kurikulum adalah kurikulum adalah seperangkat rencana dan pengaturan mengenai tujuan, isi, dan bahan pelajaran serta cara yang digunakan sebagai pedoman penyelenggaraan kegiatan pembelajaran untuk mencapai tujuan pendidikan tertentu.

Adapun pengertian menurut UU RI No. 20 Tahun 2003 tentang Sistem Pendidikan Nasional Pasal 1 Ayat 19 : "Kurikulum merupakan seperangkat rencana dan pengaturan mengenai tujuan, isi, tambahan pelajaran serta cara yang digunakan sebagai pedoman penyelenggaraan kegiatan pembelajaran untuk mencapai tujuan pendidikan tertentu”.

Jadi Manajemen Kurikulum adalah segenap proses usaha bersama untuk memperlancar pencapaian tujuan pengajaran dengan titik berat pada usaha meningkatkan kualitas belajar mengajar. Pembelajaran adalah proses interaksi peserta didik dengan pendidik dan sumber belajar pada suatu lingkungan belajar.

Secara historis, mutu sebenarnya sebagai suatu konsep yang sudah lama dikenal, tetapi kemunculannya sebagai bagian integral manajemen baru terjadi akhir-akhir ini.

Pendidikan adalah usaha sadar dan terencana untuk mewujudkan suasana belajar dan proses pembelajaran agar peserta didik secara aktif mengembangkan potensi dirinya untuk memiliki kekuatan keagamaan, pengendalian diri,kepribadian, kecerdasam, akhlak mulia, serta keterampilan yang diperlukan dirinya dan masyarakat.

Sekolah merupakan salah satu institusi sosial yang memiliki peran strategi dalam pembinaan kepribadian anak. Di dalam sekolah terjadi proses transformasi kebudayaan kepada anak. tentu saja, transformasi kebudayaan tersebut berlangsung melalui pembelajaran sesuai kurikulum yang berisikan berbagai bidang ilmu pengetahuan dan nilai-nilai yang berlaku di masyarakat.

Kelancaran pelaksanaan pendidikan disekolah sangat tergantung pada berfungsi tidaknya manajemen sekolah. Hal ini menjadi tanggung jawab utama kepala sekolah untuk mencapai sekolah yang berkualitas.

Salah satu masalah yang dihadapi dunia pendidikan adalah masalah lemahnya proses pembelajaran. Dalam proses pembelajaran, anak kurang didorong untuk mengembangkan kemampuan berpikir. Proses pembelajaran di dalam kelas diarahkan kepada kemampuan anak mengingat berbagai informasi tanpa dituntut untuk memahami informasi yang di ingatnya itu untuk menghubungkannya dengan kehidupan sehari-hari.

Lemahnya proses pembelajaran yang dikembangkan guru dewasa ini, merupakan salah satu masalah yang dihadapi di dunia pendidikan kita. Proses pembelajaran yang terjadi di dalam kelas di laksanakan sesuai kemampuan dan selera guru. Padahal pada kenyataannya kemampuan guru dalam pengelolaan pembelajaran tidak merata sesuai dengan latar belakang pendidikan guru serta motivasi kecintaan mereka terhadap profesinya. 
ada guru yang melaksanakan pengelolaan pembelajarannya dilakukan dengan sungguhsungguh melalui perencanaan yang matang, dengan memanfaatkan seluruh sumber daya yang ada dan memperhatikan taraf perkembangan intelektual dan perkembangan psikologi belajar anak. Guru yang demikian akan dapat menghasilkan lulusan yang lebih tinggi dibandingkan dengan guru yang dalam pengelolaan pembelajarannya dilakukan seadanya tanpa mempertimbangkan berbagai faktor yang bisa mempengaruhi keberhasilan proses pembelajaran.

Guru merupakan pengembang metode pembelajaran bagi kelasnya, dalam hal ini, tugas guru tidak hanya mentransfer pengetahuan akan tetapi lebih dari itu, yaitu membelajarkan anak supaya dapat berpikir integral dan komprehensif, untuk membentuk kompetensi dan mencapai makna tertinggi.

Secara garis besar, Al-Qur'an menyatakan bahwa orang-orang yang menerapkan manajemen tidaklah sama dengan orang yang tidak menerapkannya, Allah SWT berfirman:

$$
\begin{aligned}
& \text { لا يستو ي إبب النار ؤ ا جب الجنه } \\
& \text { جִب الجنه هم الفائز و ن }
\end{aligned}
$$

Artinya : "Tidak sama para penghuni

neraka dengan para penghuni surga; para penghuni surga itulah orang - orang yang memperoleh kemenangan". (QS. Al-Hasyr : 20).

Karena orang-orang yang menerapan manajemen (profesional) akan meraih kebahagiaan. Dengan demikian, manajemen memiliki peran yang vital bagi keberhasilan manusia di dalam meraih harapan dan cita-cita.

Pengawasan merupakan salah satu dari fungsi manajemen. Ilmu Manajemen diperlukan agar tujuan yang hendak dicapai bisa diraih dan efisien serta efektif. Ajaran islam sangat menmperhatikan adanya bentuk pengawasan terhadap diri terlebih dahulu sebelum melakukan pengawan terhadap orang lain. Berdasarkan Hadits, An-Nabawi yang diriwayatkan dari Ya'la Rasulullah SAW bersabda :

$$
\begin{aligned}
& \text { إن اله كتب تئ كل على لا جِّا نا } \\
& \text { Artinya : "Sesunggguhnya mewajibkan } \\
& \text { kepada kita untuk berlaku } \\
& \text { ihsan dalam segala sesuatu". }
\end{aligned}
$$

Berdasarkan Hadits tersebut, pengawasan dalam islam dilakukan untuk meluruskan yang bengkok, mengoreksi yang salah dan membenarkan yang hak.

SMP PGRI 1 Pulau Panggung, Tanggamus sebagai satu satunya Yayasan Pembina Lembaga Pendidikan dikecamatan Pulaupanggung yang dituntut konstribusinya dalam memajukan dunia pendidikan serta lebih meningkatkan kualitas baik input dan output, terlebih dengan adanya konteks otonomi dan desentralisasi pendidikan yang mana SMP PGRI dituntut untuk mandiri dalam mengelola lembaga pendidikannya termasuk dalam manajemen kurikulum untuk dapat meningkatkan mutu pendidikan. manajmen kurikuum melibatkan seluruh komponen sekolah. Tujuan pendidikan yang diprioritaskan selama ini terkadang kurang memperhatikan mutu pendidikan.

Ada beberapa persoalan yang selama ini dihadapi guru dalam pendidikan dan pembelajaran di sekolah SMP PGRI 1 Pulau Panggung diantaranya :

1. Kurikulum yang ada di sekolah hanya dianggap sebagai rambu-rambu mengajar.

2. Guru tidak memahami kurikulum, sehingga saat ada perubahan dari kurikulum KBK menuju KTSP lalu Kurikulum 2013 tidak ada perubahan yang signifikan. Yang disebabkan tidak adanya kemandirian sekolah dan diperparah oleh lemahnya sumber daya manusia. Padahal tujuan dari KTSP adalah adanya kemandirian guru.

Dari survey yang telah dilakukan di SMP PGRI 1 Pulaupanggung pada tanggal 7 Juli 2015, melalui wawancara peneliti dengan Ibu Erma yanti, S.Pd selaku Kepala SMP PGRI 1 Pulaupanggung yaitu pelaksanaan belajar mengajar harus mengunakan RPP tidak mesti dilakukan perubahan dalam setiap awal tahun pelajaran karena dianggap masih ada kesamaan dengan RPP sebelumnya. pada tahun 2008/2009, SMP PGRI 1 Pulaupanggung, Tanggamus telah menerapkan Kurikulum Tingkat Satuan Pendidikan (KTSP) yang tidak jauh berbeda dengan Kurikulum Berbasis Kompetensi (KBK), perubahan Kurikulum yang terus terjadi serta pedoman yang digunakan juga ikut berubah, maka sebagai pengelola pendidikan termasuk guru harus lebih kreatif dalam pengelolaan pembelajaran.

Kurikulum tersebut disusun oleh beberapa guru bidang studi melalui kegiatan MGMP (Musyawarah Guru Mata Pelajaran) atau melalui rapat tahun ajaran baru. Setiap pendidik harus memahami perkembangan kurikulum, karena merupakan suatu formulasi pedagogis yang paling penting dalam konteks pendidikan, dalam kurikulum akan tergambar bagaimana usaha yang dilakukan membantu siswa dalam mengembangkan potensinya, berupa fisik, intelektual, emosional dan sosial, keagamaan dsb.

Maka, disini perlu adanya Manajemen Kurikulum yang merupakan salah satu komponen vital sebuah lembaga pendidikan. Mekanisme Manajemen Kurikulum yang jelek akan sangat berpengaruh terhadap mutu pendidikannya. Pendidikan dapat dikatakan berkualitas jika berhasil mengeluarkan out-put atau lulusan yang sesuai dengan tujuan atau 
cita-cita pendidikan itu sendiri, sedangkan untuk merealisasikan tujuan pendidikan dalam proses pendidikannya banyak kendala yang dihadapi manajer dalam hal ini adalah kepala sekolah. untuk mencapai tujuan tersebut secara efektif dan efisien, maka diperlukan diantaranya adanya manajemen yang professional. Oleh sebab itu peneliti akan meneliti manajemen kurikulum pembelajaran yang ada di SMP PGRI 1 Pulaupanggung, dengan mengangkat judul Implementasi Manajemen Kurikulum Pembelajaran Dalam Meningkatkan Mutu Pendidikan

\section{B. Tujuan Penelitian}

Suatu penelitian tentu memiliki tujuan yang berfungsi sebagai pedoman, arah, dan hasil yang akan dicapai dari penelitian. karena itu tujuan dari penelitian ini yaitu : Untuk mengetahui implementasi manajamen kurikulum pembelajaran di SMP PGRI 1 Pulaupanggung.

\section{Metode Penelitian}

Jenis penelitian ini adalah penelitian Kualitatif. Penelitian kualitatif umumnya mengambil sampel lebih kecil dan lebih mengarah ke penelitian proses daripada produk dan biasanya membatasi pada satu kasus. Metode pengumpulan data dengan menggunakan metode pengamatan, metode wawancara, metode dokumentasi. Analisa yang digunakan adalah analisa logika komparatif. Proses analisis data yang peneliti gunakan yaitu analisis kualitatif dan menggunakan metode deskriptif analitik.

\section{Pembahasan}

Pemaparan penelitian ini menyajikan gambaran umum tentang implementasi manajemen kurikulum untuk meningkatkan mutu pendidikan Di SMP PGRI 1 Pulaupanggung Kabupaten Tanggamus. Penelitian ini memberikan gambaran akan pentingannya manajemen Kurikulum bagi kemajuan pendidikan khususnya pada SMP PGRI 1 Pulaupanggung sebagai pendidikan menengah yang hendaknya dikelola dengan baik, gambaran umum penelitian ini adalah Implementasi Manajemen Kurikulum dalam meningkatkan mutu pendidikan, kendalakendala yang dihadapi dalam meningkatkan mutu pendidikan dan usaha-usaha dalam meningkatkan mutu pendidikan. Subyek dari penelitian ini terdiri dari kepala SMP PGRI 1 Pulaupanggung, Waka Kurikulum, sampel Guru dan sampel Peserta didik yang ada Di SMP PGRI 1 Pulaupanggung di Kabupaten Tanggamus.
Berdasarkan observasi penelitian yang peneliti lakukan serta hasil wawancara dengan Kepala Pelaksanaan Manajemen Kurikulum dalam meningkatkan mutu pendidikan Di SMP PGRI 1 Pulaupanggung menyatakan bahwa beliau sudah berusaha melakukan manajemen kurikulum dengan sebaik-baiknya dalam rangka meningkatkan mutu pendidikan bagi peserta didik.

Dari hasil wawancara peneliti dengan Kepala Sekolah SMP PGRI 1 Pulaupanngung, pada tanggal 9 juli 2015 pukul : 08.30 WIB,Peneliti menanyakan bagaimanakah cara implementasi manajemen kurikulum terkait pembelajaran di kelas? Apakah ada kisi-kisi khusus dari sekolah dalam pembelajaran agar tujuan dari pembelajaran di sekolah berhasil? Lalu Kepala Sekolah SMP PGRI 1 Pulaupanngung menyatakan bahwa "Untuk masalah pelaksanaan proses belajar dari sekolah tidak ada kisi-kisi khusus harus seperti apa. Itu tugas masing-masing guru untuk membelajarkan siswa agar menjadi seorang pembelajar".

Dari hasil wawancara peneliti dengan salah satu Guru SMP PGRI 1 Pulaupanngung, pada tanggal 9 juli 2015 pukul : 10.30 WIB Peneliti menanyakan Bagaimanakah penerapan kurikulum KTSP dalam pembelajaran di kelas? Lalu beliau menjawab "Sejauh ini penerapan kurikulum ini berjalan baik. Banyak siswa lulusan SMP PGRI 1 Pulaupanggung melanjutkan ke Sekolah SMA sederajat yang terbaik".

Penerapan manajemen pembelajaran dalam meningkatkan mutu pendidikan di SMP PGRI 1 Pulaupanggung itu melalui beberapa tahapan yaitu:

Perencanaan kurikulum SMP PGRI 1 Pulaupanggung ini berdasarkan pada hasil evaluasi sebelumnya dan perencanaan target dan program kedepan yang disusun oleh kepala sekolah dengan seluruh staf bawahannya. Selain itu dari hasil wawancara peneliti dengan Kepala Sekolah SMP PGRI 1 Pulaupanggung, peneliti menanyakan Apakah dalam perencanaan kurikulum melakukan kerjasama dengan pihak lain? Siapa saja? Lalu Kepala Sekolah SMP PGRI 1 Pulaupanngung menyatakan bahwa "Iya, pihak lain ini dari YPLP dan komite" sedangkan menurut pernyataan dari Waka Kurikulum SMP PGRI 1 Pulaupanngung "Perencanaan kurikulum program kedepan yang disusun Setelah loka karya, tindak lanjutnya yaitu mengadakan workshop kemudian silabus KTSP, dan pada awal tahun kita juga mengadakan sosialisasi kepada peserta didik, orang tua siswa. Dimana dalam sosialisasi tersebut kita jelaskan apa dan bagaimana kurikulum KTSP itu”. 
Kepala Sekolah Menyatakan bahwa "Untuk masalah perencanaan kurikulum itu kan sudah ada dalam peraturan pemerintah, tinggal kita yang menyesuaikan dengan kondisi siswa dan kondisi sekolah. "Kalau kita menyusun kurikulum kita akan mempertimbangkan banyak hal, visi dan misi sekolah, kesesuaian pelaksanaan kurikulum sebelumnya, nah ini mungkin yang anda maksud. Kalau tidak ada kesesuaian dengan tujuan sekolah maka sekolah akan mengevaluasinya. Baik itu mengevaluasi kompetensi guru, mengevaluasi materi, mengevaluasi siswa, atau hal lain yang berkaitan dengan pelaksanaan proses belajar".

Pengorganisasian kurikulum meliputi membagi tugas mengajar bagi guru sesuai dengan bidang keahlian masing-masing, mengupayakan agar guru mengajar 5 hari dalam 1 minggu, menyususn jadwal kegiatan perbaikan/remidi, mengadakan les dan try out, menyususn jadwal kegiaatn ektra kurikuler, menyusun jadwal pengajaran bagi guru tentang IPTEK, dan menyusun jadwal pertemuan guruguru secara bergiliran.

Pelaksanaan kurikulum meliputi kegiatan awal pembelajaran,Metode pembelajaran, Media pembelajaran, kegiatan akhir pembelajaran.

Hasil wawancara salah satu guru SMP PGRI 1 Pulaupanggung menyatakan bahwa "Kegiatan awal seperti berdoa itu udah pasti ya mba. Menyanyikan lagu kebangsaan untuk siswa baru, presensi, menyampaikan ramburambu materi yang akan diajarkan apa saja. Sedangkan untuk kegiatan inti jelas penyampaian materi". Menurut beliau "Saya jarang sekali menulis, untuk menyampaikannya saya menggunakan powerpoint atau film, dan disela-sela itu ada Tanya jawab, Ada LCD, internet dengan menggunakan modem untuk mengetahui peristiwa yang ada pada saat itu, film atau yang lain. Saya selalu memanfaatkan media yang ada, Sedangkan untuk kegiatan akhir ada presentasi siswa, menyimpulkan dan pemberian tugas".

Hasil wawancara dengan kepala sekolah SMP PGRI 1 Pulaupanggung menyatakan bahwa "Setiap saat harus ada evaluasi program, baik temporer maupun terprogram. Untuk yang terprogram dilakukan setiap akhir tahun, di luar evaluasi yang sub-sub missal bagaimana pelaksanaan ulangan umum. Jadi secara kontinyu kita lakukan evaluasi. Dari hasil evaluasi itu, kita menyusun program yang bisa menindaklanjuti hasil evaluasi itu. Karena prinsip kami "hari esok harus lebih baik dari hari ini". Evaluasi di luar sistem bisa juga dilakukan oleh komite, orang tua siswa dan masyaarakat, Setelah kita evaluasi maka kita akan memperbaiki hal yang perlu diperbaiki, dan meningkatkan yang sudah berjalan dengan baik.

Dari hasil wawancara peneliti dengan Waka Kurikulum SMP PGRI 1 Pulaupanngung, pada tanggal 11 juli 2015 pukul : 09.30 WIB,Peneliti menanyakan Bagaimanakah evaluasi yang dilakukan sekolah dalam pelaksanaan kurikulum? Kapan evaluasi kurikulum dilakukan? Beliau menjawab "Iya mba, setiap tahun kita mengadakan evaluasi dimana minimal evaluasi itu dilaksanakan sekali dalam setahun yaitu melalui audit internal dan audit eksternal (dari pusat)".

Dari hasil wawancara peneliti dengan guru Mata Pelajaran IPS pada tanggal 11 juli 2015,Peneliti menanyakan Model Penilaian apa yang anda gunakan dalam pembelajaran? Apakah model penilaian berbasis kelas, model test berupa uraian, pilihan ganda? Kemudian pada saat diskusi juga melihat dan melakukan penilaian melalui keaktifan siswa? Selain itu apakah anda memberikan tugas-tugas, remidi dan pengayaan? Beliau menjawab "Untuk evaluasi ada ulangan harian, mid semester dan ujian akhir semester. Evaluasi itu di luar tugas individu dan kelompok. Selain kognitif saya juga mengevaluasi aspek afektif siswa seperti perilkau keseharian dalam mengikuti pelajaran saya. Sedangkan untuk aspek psikomotorik tidak terlalu dominan dalam pembelajaran sejarah".

\section{E. Penutup}

\section{1) Kesimpulan}

Dari hasil penelitian tentang Implementasi Manajemen Kurikulum Dalam Meningkatan Mutu Pendidikan Di SMP PGRI 1 Pulaupanggung telah dipaparkan terdahulu maka dapat disimpulkan bahwa:

Penerapan manajemen pembelajaran dalam meningkatkan mutu pendidikan di SMP PGRI 1 Pulaupanggung itu melalui bebetapa tahapan yaitu:

a. Perencanaan kurikulum di SMP PGRI 1 Pulaupanggung ini berdasarkan pada hasil evaluasi sebelumnya dan perencanaan target dan program kedepan yang disusun oleh kepala sekolah dengan seluruh staf bawahannya.

b. Pengorganisasian kurikulum meliputi membagi tugas mengajar bagi guru sesuai dengan bidang keahlian masing-masing, mengupayakan agar guru mengajar 5 hari dalam 1 minggu, menyususn jadwal kegiatan perbaikan/remidi, mengadakan les dan try out, menyususn jadwal kegiaatn ektra kurikuler, menyusun jadwal pengajaran bagi guru tentang IPTEK, dan menyusun jadwal pertemuan guru-guru secara bergiliran. 
c. Pelaksanaan kurikulum meliputi kegiatan awal pembelajaran,Metode pembelajaran, Media pembelajaran, kegiatan akhir pembelajaran.

d. Evaluasi kurikulum yaitu menggunakan bentuk evaluasi aspek kognitif, aspek afektif dan aspek psikomotorik.

\section{2) Saran}

Berdasarkan laporan hasil penelitian, dapat diketahui bahwa manajemen kurikulum yang dilaksanakan di SMP PGRI 1 Pulaupanggung sudah cukup baik. Namun masih perlu ada beberapa peningkatan dan perbaikan dalam sistem pembagian waktu pembelajaran pada tiap-tiap program oleh karena itu, peneliti menyarankan bebrapa hal yang dapat dijadikan rekomendasi dalam perbaikan penerapan manajemen pembelajaran dalam meningkatkan mutu pendidikan di SMP PGRI 1 Pulaupanggung. Saran-saran tersebut adalah sebagai berikut:

\section{Bagi Para Pengelola Pendidikan}

Bahwasannya Kepala Sekolah merupakan orang yang paling bertanggung jawab dalam keberhasilan manajemen kurikulum dan proses pendidikan disekolah, sedangkan para wakil kepala sekolah dan guru merupakan unsur pendukung yang berfungsi membantu kepala sekolah dalam menjalankan tugasnya. Oleh karena itu dalam rangka manajemen kurikulum yang unggul dan berkualitas, maka diperlukan upaya bersama yang dimotori oleh kepala sekolah dalam rangka meningkatkan mutu pendidikan dan pembelajaran disekolah secara kontinyu dan berkesinambungan.

\section{Bagi Para Guru}

Guru merupakan salah satu komponen terpenting dalam pelaksanan kurikulum didalam kelas melalui proses belajar mengajar. Oleh karena itu, penting sekali adanya kompetensi dan professional guru dalam mengajar serta perlu diciptakan suasana yang kondusif dalam kegiatan nelajar mengajar. Bahwa guru dituntut untuk selalu kreatif dan inovatif dalam rangka meningkatkan kualitas pembelajaran disekolah.

\section{Bagi Para Praktisi Pendidikan}

Fenomena sekolah unggulan, khususnya pada lembaga pendidikan umum yang bercirikan Islam merupakan sesuatu yang harus lebih diperhatikan lagi, karena keberadaan mereka akan menjadi pilot project bagi pendidikan menengah umum yang bercirikan Islam pada khususnya dan pendidikan menengah umum yang ada di Indonesia pada khususnya.

\section{DAFTAR PUSTAKA}

Achmad,2014. Mutu Pendidikan.Jakarta
:Guraru

لئ اله Yakni Anas bin malik r.a

Al Qur'an dan Terjemahan Kementrian Agama RI, 2010, Diterjemahkan oleh Lajnah Pentashih Mushaf, Bandung: CV Fokusmedia

Anisari, A., Purwanti, E., \& Masrur, M. (2017). Strategi Kepala Sekolah Dalam Meningkatkan Mutu Pembelajaran Di SMP Nurul Islam Kelurahan Garuntang Kecamatan Bumi Waras Kota Bandar Lampung. Jurnal Manajemen Pendidikan Islam Al-Idarah, 1(1), 1-9.

Bungin ,Burhan,2001. Metodologi Penelitian Sosial .Surabaya: Airlangga

Consueli G, Selvia, 2001. Pengantar Metode . Jakarta : Universitas Indonesia UI-Press

D.L,Goetsch, dan Davis, 1994. Introduction to Total Quality: Quality, Productivity, competitiveness. New York :Prentice Hall International

Fauzi, 2013.Manajemen Itu Mudah.Jakarta : PT Raja Grafindo Persada

Gitosudarmo,Indriyo,2008.Manajemen Pendidikan. Yogyakarta : AditiyaMedia

Goode,Willian J dan K.Hat,Paul,1952. Methode in Social Research. TokyoMcGraw Hiil

Hadun ,Aminul dan Harjono, 1998. Metodologi Penelitian Pendidikan. Bandung : Toha Putra

Handoko,1996. Manajemen Personalia danSumber Daya Manusia. Yogyakarta : BPFE

Harsono,Hanifah, 2002. Implementasi Kebijakan dan Polotik. Bandung:Remaja Rosdakarya

Hasan,M.Iqbal,1994. Pokok-Pokok Materi Metodologi Penelitian dan Aplikasinya. Jakarta: PT Rineka Cipta

Indria, Nina, Observasi Peneliti Terhadap Peserta didik kelas VIII, (Tercatat tanggal 11 Juli 2015)

Indriyo,Gitosudarmo, 2008. Manajemen Pendidikan.Yogyakarta : AditiyaMedia

Iskandar, 2009.Metodologi Penelitian Pendidikan dan Sosial Kuantitaif dan Kualitatif.Jakarta:GP. Press

Koentjaraningrat,1977.Metode-metode Penelitian Masyarakat.Jakarta: Gramedia

Kusuma, N., \& Purwanti, E. (2017). Pengaruh Kompetensi Pedagogik Dan Manajemen Pembelajaran Terhadap Penjaminan Mutu Pada Universitas Sang Bumi Ruwa Jurai Lampung. Indonesian Journal of Educational Counseling, 1(2), 209-226.

Lexy J,Moleong ,2004.Metodelogi Penelitian Kualitatif. Bandung:Remaja Rosdakarya

lovelock,1994.C.Product Plus :How Product + Service $=$ Competitive Advantage. $\mathrm{New}$ 
York :MCGraw Hill

Marno,dan Supriyatno, Triyo,2008.Manajemen dan Kepemimpinan Pendidikan Islam.Bandung :PT. Refika Aditama

Moleong,2007.Metode Penelitian

Kualitatif.Bandung : Remaja Rosdakaya

Mulyana,Deddy, 2004. Metodologi Penelitian Kualitatif; Peradigma Baru Ilmu Komunikasi Dan Ilmu Sosial Lainnya.Bandung: PT Remaja Rosdakarya

Mulyasa,E,2013.Manajemen Berbasis Sekolah: Konsep, Strategi dan Implementasi. Bandung: Sinar Baru

Muhadjir ,Noeng, 1996.Metode Penelitian Kualitatif.Yogyakarta: Rake Sarasia

Muhammad Ali al Shabuni, 2010. Al Qur'an dan Terjemahan Kementrian Agama RI Diterjemahkan oleh Lajnah Pentashih Mushaf. Bandung: CV Fokusmedia

Nasution, 1988.Metode Penelitian NaturalistikKualitatif. Bandung: Tarsito

Nasution ,S,2011.Metode Research (Penelitian Ilmiah).Jakarta: Bumi Aksara

Ramayulis,2006.Kamus Besar Bahasa Indonesia.Jakarta:PT.Rineka Cipta

Rusman,2007. Manajemen Kurikulum. Bandung : Remaja Rosdakaya.

Robbins dan P,Stephen 2007.Prilaku Organisasi.Jakarta :Salemba Empat

Sanjaya,Wina,2007.Strategi Pembelajaran Berorientasi StandarProses Pendidikan.Jakarta : Kencana

S,Margono, 2000. Metodologi Penelitian Pendidikan.Jakarta: PT Rineka Cipta

Sanjaya,Wina,2007.Strategi Pembelajaran Berorientasi StandarProses Pendidikan.Jakarta : Kencana

Setiawan,Guntur,2005. Al Bukhari: dari Sahabat Rasulullah لئ / له علبه وسلم Yakni Anas bin malik r.a (Beirut : Dar al Fikr, tt)

Setiawan,Guntur, Al Bukhari 6010 dalam AnNabawi: (Beirut : Dar al Fikr, tt)

Siswanto,2005.

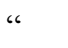

Pengantar Manajemen”.Jakarta: Bumi Aksara

Subagyo,Joko, 2004. Metode Penelitian Dalam Teori dan Praktik. Jakarta: PT Rineka Cipta

Sudjana nana dan Ibrahim,1998.Penelitian dan Penelitian Kualitatif.Bandung : Sinar Baru

Sugiono,2008.Metodologi Penelitian Pendidikan Pendekatan Kuantitatif, Kualitatif dan $R \& D$.Bandung : Alfabeta

Suharsimi,Arikunto,2006.Prosedur Penelitian Suatu Pendekatan Praktik.Jakarta:PT.Rineka Cipta
Suharsimi,Arikunto dan yuliana,Lia,2008. Manajemen Pendidikan. Yogyakarta :Aditiya Media

Suharsimi,Arikunto,2006Prosedur Penelitian: Suatu Pendekatan Praktek. Jakarta, Rineka Cipta

Sukandarrumidi,2004.

Metodologi Penelitian. Yogyakarta : Gajah Mada University Press

Sulustyorini,2009.Manajemen Pendidikan Islam (konsep,strategi dan aplikasi. Yogyakarta : TERAS

Suryadi,Ace,2007.Mutu Pendidik. Bandung : Remaja Rosdakarya

Trianto,2009.Mendesain Model Pembelajaran Inovatif-Progresif.Jakarta : Kencana

Undang-Undang SISDIKNAS Nomor 20 Tahun

2003 tentang Pendidikan

UU RI No. 20 Tahun 2003 tentang Sistem

Pendidikan Nasional Pasal 1 Ayat 20

UU RI No. 20 Tahun 2003 tentang Sistem

Pendidikan Nasional Pasal 1 Ayat 19

Usman,Nurdin,2002. Konteks Implementasi Berbasis Kurikulum.Jakarta: Bumi Aksara

Wawancara dengan Ibu Erma Yanti selaku $\begin{array}{llll}\text { Kepala } & \text { SMP } & \text { PGRI } & 1\end{array}$ Pulaupanggung,Tanggamus

Wawancara dengan Ibu Masripah selaku Waka Kurikulum SMP PGRI 1 Pulaupanggung,Tanggamus

Wawancara dengan Bpk. Dedi Radiman selaku $\begin{array}{llll}\text { Guru IPS SMP } & \text { PGRI } 1\end{array}$ Pulaupanggung,Tanggamus

Wikipedia,2015.http://www.Google.Manajemen Kurikulum.go.id/

Wikipedia,2014.http://www.Google.Manajemen Kurikulum.go.id/

Zais,2012.Kurikulum Pendidikan"What The Man Can Become”.Padang : Bung Hatta University Press 